ORIGINAL ARTICLE

\title{
Evaluation of "point of care" devices in the measurement of low blood glucose in neonatal practice
}

\author{
H T Ho, W K Y Yeung, B W Y Young
}

Arch Dis Child Fetal Neonatal Ed 2004;89:F356-F359. doi: 10.1136/adc.2003.033548

See end of article for authors' affiliations

.....................

Correspondence to: Dr Ho, Department of Paediatrics and Adolescent Medicine, Pamela Youde Nethersole Eastern Hospital, 3 Lok Man Road, Chai Wan, Hong Kong SAR, China; brianyon@ netvigator.com

Accepted 15 September 2003

\begin{abstract}
Background: Low blood glucose in newborns is difficult to detect clinically. Hence a reliable "point of care" device (glucometer) for early detection and treatment of low glucose is needed.

Objective: To evaluate the performance of five readily available glucometers for the detection of low blood glucose in newborn infants.

Method: Glucostix measurements were taken for newborns with risk factors using a Reflolux $\mathrm{S}$ (Boehringer) glucometer. If the initial reading was low $(<2.6 \mathrm{mmol} / \mathrm{l})$, further measurements were taken with two other glucometers (phase I, Advantage and Glucotrend (Roche); phase II, Elite XL (Bayer) and Precision (Abbott)), and plasma glucose was measured in the laboratory (Aeroset; Abbott).

Results: Over 10 months, 101 specimens were collected from 71 newborns (57 in phase I; 44 in phase II). The Advantage glucometer usually overestimated blood glucose with a mean difference of $1.07 \mathrm{mmol} / \mathrm{l}$ $(p<0.01)$ at all low glucose ranges. The Glucotrend, Precision, and Elite XL glucometers performed better; the mean differences were not significantly different from the laboratory measured value $(0.17 \mathrm{mmol} / \mathrm{l}(\mathrm{p}=0.37) ;-0.12 \mathrm{mmol} / \mathrm{l}(\mathrm{p}=0.13)$, and $0.24 \mathrm{mmol} / \mathrm{l}(\mathrm{p}=0.13)$ respectively). For detection of glucose concentrations $<2.6 \mathrm{mmol} / \mathrm{l}$, the Precision glucometer had the highest sensitivity $(96.4 \%)$ and negative predictive value $(90 \%)$. For lower glucose concentrations $(<2.0 \mathrm{mmol} / \mathrm{l})$, the Glucotrend glucometer performed even better (sensitivity 92.3\%, negative predictive value 96.3\%).

Conclusion: Point of care devices should have good precision in the low glucose concentration range, sensitivity, and accuracy for early detection of neonatal hypoglycaemia. None of the five glucometers was satisfactory as the sole measuring device. The Glucotrend and Precision glucometers have the greatest sensitivity and negative predictive value. However, confirmation with laboratory measurements of plasma glucose and clinical assessment are still of the utmost importance.
\end{abstract}

ow blood glucose is common in newborn infants. Affected infants usually have no symptoms and are therefore easily - missed. Prolonged hypoglycaemia may result in long term adverse neurodevelopmental outcome. ${ }^{1-3}$ However, screening all newborn babies would be invasive. The yield is low and not cost effective. Therefore, in 1993, the American Academy of Pediatrics recommended selective testing for high risk cases. Screening for hypoglycaemia and early feeding were recommended only for infants with risk factors, such as intrauterine growth retardation and infants of maternal gestational diabetes. ${ }^{4}$

The optimum method for measuring plasma glucose is the hexokinase method. As it is usually performed in the main laboratory, results are not available quickly enough for timely appropriate treatment. Therefore "point of care" devices (reflectance glucometers) are often used for measurement of whole blood glucose concentration in nursery and neonatal intensive care units. Low blood glucose concentration is then confirmed in the main laboratory.

Unfortunately, glucometer measurement is problematic. This is especially true for newborn babies. Currently used glucometers were initially developed for glucose monitoring in adult patients with diabetes. Many studies have shown that their results correlate well with laboratory measured plasma glucose in the normoglycaemic and hyperglycaemic range, but are not satisfactory in the lower range. However, our main concern in newborn babies is the low blood glucose range.

In 1994, the American Diabetic Association (ADA) recommended that a glucometer should achieve a total error (system + user) of less than $10 \%$ for the plasma glucose concentration range $1.6-22.2 \mathrm{mmol} / \mathrm{l}(30-400 \mathrm{mg} / \mathrm{dl}){ }^{5}$ It was also ascertained by the US National Committee for Clinical Laboratory Standards (NCCLS) in 1994 that for glucose concentrations less than $5.5 \mathrm{mmol} / \mathrm{l}(100 \mathrm{mg} / \mathrm{dl})$, discrepancies should be no more than $0.83 \mathrm{mmol} / \mathrm{l}(15 \mathrm{mg} / \mathrm{dl}){ }^{6}$

The haemoglobin concentration and packed cell volume in newborns also affect the results of whole blood Glucostix measurement. Anaemia falsely raises and polycythaemia falsely depresses glucometer readings. In general, whole blood glucose concentrations are 10-15\% lower than plasma glucose measurements.

Cornblath et $a l^{7}$ recommended operational thresholds at which clinicians should consider intervention. This threshold varies with gestation, breast feeding, and the presence of risk factors. If the plasma glucose concentration is less than $2.0 \mathrm{mmol} / \mathrm{l}(36 \mathrm{mg} / \mathrm{dl})$, close surveillance and intervention should be considered. For preterm infants, a higher cut off value of $2.6 \mathrm{mmol} / \mathrm{l}(47 \mathrm{mg} / \mathrm{dl})$ was suggested, as it may be correlated with abnormal neuromotor and intellectual performance at 18 months of age. Therefore the practice in our hospital is to screen for whole blood glucose using a glucometer in infants with risk factors. This is subsequently confirmed by plasma glucose measurement if it is less than $2.6 \mathrm{mmol} / \mathrm{l}^{78}$

There are many different types of glucometers available for point of care glucose measurement. Various studies have evaluated their accuracies. ${ }^{9-16}$ The Reflolux S glucometer was the one commonly used in our neonatal unit, although, in our experience, it usually underestimated the true plasma

Abbreviations: ADA, American Diabetic Association; NCCLS, National Committee for Clinical Laboratory Standards; NPV, negative predictive value; PPV, positive predictive value 
concentration. New portable glucometers have recently been introduced on to the market. We investigated whether any of them give more accurate results especially in a defined low range.

The aim of this study was to evaluate the performance of five readily available glucometers in detecting low blood glucose concentration in newborn infants.

\section{METHODS}

Newborns with risk factors-for example, prematurity, small or large for gestational age-were screened for capillary blood glucose initially with a Reflolux S glucometer (Boehringer, Mannheim, Germany). If the initial measurement was less than $2.6 \mathrm{mmol} / \mathrm{l}(47 \mathrm{mg} / \mathrm{dl})$, it was confirmed by plasma glucose measurement in the main laboratory using the hexokinase method (Aeroset; Abbott Laboratories, Abbott Park, Illinois, USA), which is under regular quality control ${ }^{17}$; results were available in one hour. To evaluate the performance of different commonly used glucometers in the hypoglycaemic range, further measurements were performed using two other glucometers when blood for plasma glucose was taken for confirmation. In the first phase of the study, Advantage and Glucotrend glucometers (Roche, Nutley, New Jersey, USA) were used for comparison. Elite XL (Bayer, Tarrytown, New York, USA) and Precision (Abbott, Benford, Massachusetts, USA) were then tested in the second phase. In order to be comparable with normal clinical situations, haemoglobin and packed cell volume were not checked unless anaemia or polycythaemia was clinically suspected. Our nursing staff were well experienced in the use of the different glucometers; there was no specially selected group of operators. As the study was performed as part of routine clinical procedure for infants with risk factors, individual specific consent was not obtained. The study was approved by the Department of Paediatrics, Pamela Youde Nethersole Eastern Hospital, Hong Kong.

\section{Statistical analysis}

The SPSS program (version 11.5) was used for statistical analysis. The method of residuals was used to compare the differences between the plasma glucose concentration and the glucometer reading (residuals); the mean (SD) of the mean difference was also calculated. The total error and discrepancies were also calculated according to the standard recommendations by ADA and NCCLS. The difference (d) between the glucometer reading and the laboratory measured plasma glucose concentration was then plotted against the corresponding glucose mean. ${ }^{18}$ The limits of agreement $(\mathrm{d}-2 \mathrm{SD}, \mathrm{d}+2 \mathrm{SD})$ were also calculated. Lastly, as our threshold for plasma glucose confirmation was set at less than $2.6 \mathrm{mmol} / \mathrm{l}(47 \mathrm{mg} / \mathrm{dl})$, the sensitivity, specificity, positive and negative predictive values (PPV and NPV) for detection of plasma glucose less than $2.6 \mathrm{mmol} / \mathrm{l}(47 \mathrm{mg} / \mathrm{dl})$ and $2.0 \mathrm{mmol} / \mathrm{l}(36 \mathrm{mg} / \mathrm{dl})$ were determined. The glucometer data displayed as "low" were not included in the calculation of mean difference and standard deviation, but were included in the sensitivity, specificity, PPV, and NPV calculations.

\section{RESULTS}

Over a period of 10 months, a total of 101 specimens had been collected from 71 newborns (57 in phase I, 44 in phase II). The median gestational age was 38 weeks (range 36-41). The measurements were performed at a median age of 1 day (range 0-3).

According to the ADA standard, none of the glucometers tested were satisfactory. Those that performed better (Glucotrend and Precision) had only 51\% and $46.5 \%$ of tests that achieved a total error of less than $10 \%$. However, these glucometers could achieve (94.5\% and $86.0 \%$ respectively) the recommendation of NCCLS that measurement discrepancies should be less than $0.83 \mathrm{mmol} / \mathrm{l}$ for detecting glucose concentrations less than $5.5 \mathrm{mmol} / \mathrm{l}$ (table 1).

Only two measurements were indicated as "low" by the Reflolux S glucometer. None were found with the other glucometers tested. Using the method of residuals and the Bland and Altman plot, the Reflolux S glucometer usually underestimated the plasma glucose concentrations especially in the range $2.5-3.5 \mathrm{mmol} / \mathrm{l}$. Their mean differences were $0.34 \mathrm{mmol} / \mathrm{l}(95 \% \mathrm{CI}-0.64$ to $-0.2 \mathrm{l} ; \mathrm{p}<0.01)$ in phase I and $0.27 \mathrm{mmol} / \mathrm{l}(95 \% \mathrm{CI}-0.42$ to $-0.12 ; \mathrm{p}<0.01)$ in phase II. The Advantage glucometer usually overestimated, with a mean difference (d) of $1.07 \mathrm{mmol} / \mathrm{l}$ (95\% CI 0.21 to 0.59 ; $\mathrm{p}<0.01)$. This occurred at all ranges of low blood glucose concentration studied. For the Glucotrend, Precision, and Elite XL glucometers, there were no significant differences from the laboratory measurements. Their mean differences were $0.17 \mathrm{mmol} / \mathrm{l}$ (95\% CI -0.79 to $0.21 ; p=0.37)$; $-0.12 \mathrm{mmol} / \mathrm{l}(95 \% \mathrm{CI}-0.27$ to $0.34 ; \mathrm{p}=0.13)$, and $0.24 \mathrm{mmol} / \mathrm{l}(95 \% \mathrm{CI}-0.73$ to $0.55 ; \mathrm{p}=0.13)$ respectively (table 1). Figure 1 shows the mean difference (d) and limits of agreement $(+2 \mathrm{SD},-2 \mathrm{SD})$ for the different glucometers (Bland and Altman plot).

When it was used as a screening device with confirmation by laboratory plasma glucose, the "low" measurements were also included in the statistical calculations. The Precision glucometer had the best sensitivity (96.4\%) and NPV (90\%) in the detection of neonatal hypoglycaemia $(<2.6 \mathrm{mmol} / \mathrm{l})$. The Glucotrend glucometer was the second best with a sensitivity of $83.3 \%$ and NPV of $82.1 \%$. For severe hypoglycaemia $(<2.0 \mathrm{mmol} / \mathrm{l})$, Glucotrend performed even better; the sensitivity was $92.3 \%$ and NPV $96.3 \%$ (table 2 ).

\begin{tabular}{|c|c|c|c|c|c|}
\hline & \multicolumn{3}{|c|}{ Glucometer - laboratory reading ( $\mathrm{mmol} / \mathrm{l})$} & \multirow{2}{*}{$\begin{array}{l}\text { Percentage with } \\
\text { total error }<10 \% \\
\text { (ADA) }\end{array}$} & \multirow{2}{*}{$\begin{array}{l}\text { Percentage with } \\
\text { discrepancy } \\
\leqslant 0.83 \mathrm{mmol} / \mathrm{l} \text { (NCCLS) }\end{array}$} \\
\hline & Mean & SD & $95 \% \mathrm{Cl}$ & & \\
\hline \multicolumn{6}{|l|}{ Phase I } \\
\hline Glucotrend & 0.168 & 0.876 & -0.79 to 0.21 & 51.0 & 94.5 \\
\hline Advantage & 1.067 & 2.280 & 0.21 to 0.59 & 20.0 & 81.5 \\
\hline Reflolux S & -0.344 & 0.919 & -0.64 to -0.21 & 26.3 & 68.4 \\
\hline \multicolumn{6}{|l|}{ Phase II } \\
\hline Elite XL & 0.241 & 1.004 & -0.73 to 0.55 & 38.1 & 85.7 \\
\hline Precision & -0.116 & 0.488 & -0.27 to 0.34 & 46.5 & 86.0 \\
\hline Reflolux S & -0.268 & 0.496 & -0.42 to 0.12 & 29.5 & 88.6 \\
\hline
\end{tabular}


Phase I
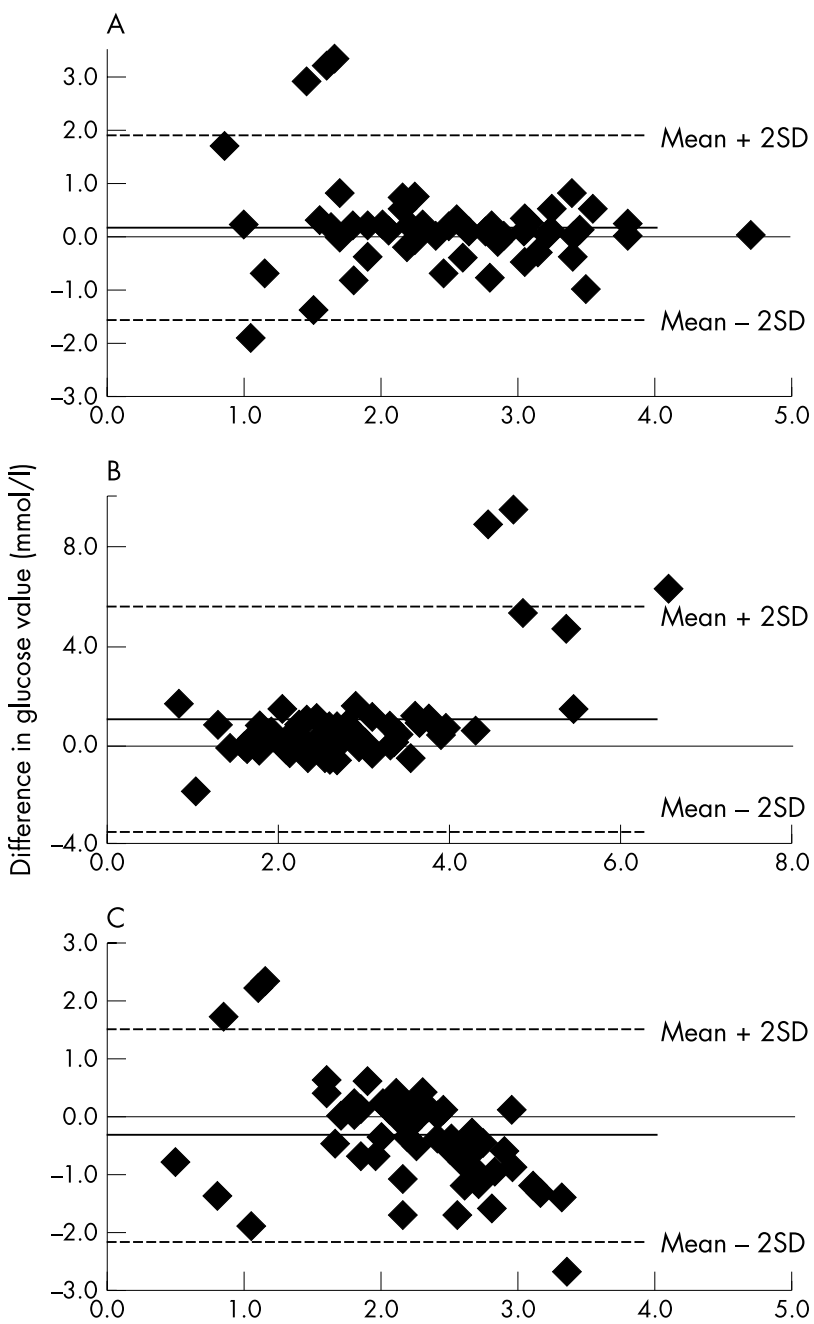

Phase II
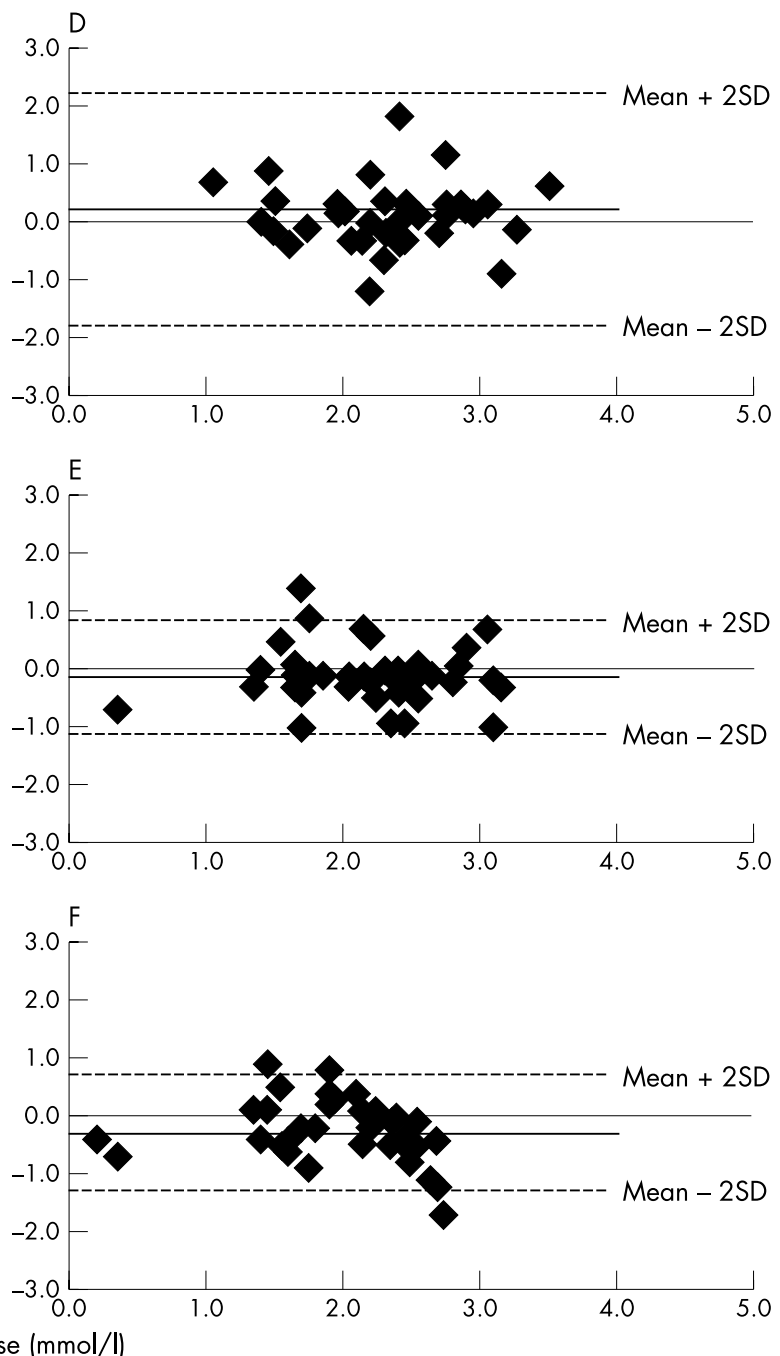

Figure 1 Capillary blood glucose (glucometer) versus plasma glucose (hexokinase method). The glucose concentration obtained using the glucometer minus the plasma glucose concentration measured by the hexokinase method is plotted against the mean of the two values. (A) Glucotrend; (B) Advantage; (C) Reflolux S; (D) Elite XL; (E) Precision; (F) Reflolux S.

\section{DISCUSSION}

Many new glucometers have recently become available for blood glucose screening and are claimed to be good for use in newborn infants. Although many studies have been performed to determine the accuracy of point of care devices for measuring blood glucose concentrations, this study concentrated on the low glucose range, which is of most concern in the neonate. In our experience, the Reflolux $S$ glucometer usually underestimates plasma glucose concentrations. Our results confirm this, showing a mean difference of $0.27-0.34$ (SD 0.50-0.92). Therefore we decided to use it to screen for low values and then to test two newer glucometers when the value needed to be confirmed.

To simulate the real clinical situation, we did not check the packed cell volume in every case, only if anaemia or polycythaemia was clinically suspected. This should seldom miss

Table 2 Sensitivity, specificity, and positive and negative predictive values of glucometers for detection of hypoglycaemia $(<2.6$ and $<2.0 \mathrm{mmol} / \mathrm{l})$

\begin{tabular}{|c|c|c|c|c|c|c|c|c|}
\hline & \multicolumn{4}{|c|}{ Hypoglycaemia $<2.6 \mathrm{mmol} / \mathrm{l}$} & \multicolumn{4}{|c|}{ Hypoglycaemia $<2.0 \mathrm{mmol} / \mathrm{l}$} \\
\hline & Sensitivity (\%) & Specificity (\%) & PPV (\%) & NPV (\%) & Sensitivity (\%) & Specificity (\%) & PPV (\%) & NPV (\%) \\
\hline \multicolumn{9}{|l|}{ Phase I } \\
\hline Glucotrend & 83.3 & 92 & 92.6 & 82.1 & 92.3 & 61.9 & 42.9 & 96.3 \\
\hline Advantage & 46.7 & 79.2 & 73.7 & 54.3 & 64.3 & 75 & 50 & 86.1 \\
\hline Reflolux S & 100 & - & 64.8 & - & 69.2 & 83.3 & 56.3 & 89.7 \\
\hline \multicolumn{9}{|l|}{ Phase II } \\
\hline Elite XL & 65.5 & 69.2 & 82.6 & 47.4 & 60 & 92.6 & 81.8 & 80.6 \\
\hline Precision & 96.4 & 60 & 81.8 & 90 & 75 & 88.9 & 80 & 85.7 \\
\hline Reflolux S & 100 & - & 68.2 & - & 70.6 & 88.9 & 80 & 82.8 \\
\hline
\end{tabular}


cases of polycythaemia which may seriously affect the whole blood glucose measurement.

According to the ADA recommendation in 1994, none of the five glucometers could achieve a total error (system + user) of less than $10 \%$ ranging from 1.6 to $22.2 \mathrm{mmol} / \mathrm{l}$. According to the NCCLS standard, the Glucotrend glucometer performed satisfactorily in more than $90 \%$ of cases, and the other glucometers in more than $85 \%$ of cases.

The Advantage glucometer usually overestimated plasma glucose in all ranges, and the Reflolux $\mathrm{S}$ glucometer underestimated plasma glucose concentrations. A similar study on the Advantage glucometer also showed an overestimation of $0.7 \mathrm{mmol} / \mathrm{l}$ (SD 0.62). ${ }^{19}{ }^{20}$ Our results indicate that the performance of the Advantage glucometer was even poorer in all ranges of low blood glucose. Both situations are unsatisfactory, as they would result in either a genuine hypoglycaemic case being missed or overtreatment. The Glucotrend and Precision glucometers showed the smallest differences from plasma glucose values.

Our results show that none of the five glucometers should be used alone for blood glucose measurement. However, if used as the initial screening device followed by confirmation by laboratory measured plasma glucose, a high sensitivity and NPV in detecting glucose concentrations less than $2.6 \mathrm{mmol} / \mathrm{l}$ (our operation threshold) and less than $2.0 \mathrm{mmol} / \mathrm{l}$ (more severe hypoglycaemia) are the most important. We found that the Glucotrend and Precision glucometers had the highest sensitivity and NPV.

\section{CONCLUSION}

A good screening device for neonatal hypoglycaemia should have good precision in the low concentration range and high sensitivity and NPV. We conclude that none of the five glucometers tested was satisfactory as the sole device for diagnosing neonatal hypoglycaemia. Although the Glucotrend and Precision glucometers had the highest sensitivity and NPV in detecting hypoglycaemia, confirmation with laboratory measurements of plasma glucose and clinical assessment of the infant are still of the utmost importance. Until other non-invasive (for example, near infrared spectroscopy ${ }^{21}$ ) or continuous (for example, subcutaneous microdialysis ${ }^{22}$ ) monitoring techniques are commonly available, screening with an appropriate bedside glucometer and subsequent plasma glucose confirmation will be the practical choice.

\section{Authors' affiliations}

H T Ho, W K Y Yeung, B W Y Young, Department of Paediatrics and Adolescent Medicine, Pamela Youde Nethersole Eastern Hospital, Hong Kong SAR, China

\section{REFERENCES}

1 Lucas A, Morley R, Cole TJ. Adverse neurodevelopmental outcome of moderate neonatal hypoglycaemia. BMJ 1988;297:1304-8.

2 Koh THHG, Aynsley-Green A, Tarbit M, et al. Neural dysfunction during hypoglycaemia. Arch Dis Child 1988;63:1353-8.

3 Duvanel CB, Fawer CL, Cotting J, et al. Long-term effects of neonatal hypoglycemia on brain growth and psychomotor development in small-for-gestational-age preterm infants. J Pediatr 1999; 134:492-8.

4 American Academy of Pediatrics. Routine evaluation of blood pressure, hematocrit, and glucose in newborns (RE9322). Pediatrics 1993;92:474-6.

5 American Diabetic Association. Consensus statement: self-monitoring of blood glucose. Diabetes Care 1994;17:81-6.

6 National Committee for Clinical Laboratory Standards. Ancillary (bedside) blood glucose testing acute and chronic care facilities; approved guidelines. NCCLS 1994; 14:C30A.

7 Cornblath M, Hawdon JM, Williams AF, et al. Controversies regarding definition of neonatal hypoglycemia: suggested operational thresholds. Pediatrics 2000;105:1141-5.

8 Williams AF. Hypoglycaemia in the newborn: a review. Bull WHO 1997:75:261-90.

9 Kirkham P, Watkins A. Comparison of two reflectance photometers in the assessment of neonatal hypoglycaemia. Arch Dis Child Fetal Neonatal Ed 1995;73:F170-3.

10 PoirierJean-Yves, Guilhem I, Prieur NL, et al. Clinical and statistical evaluation of self-monitoring blood glucose meters. Diabetes Care 1998;21:1919-24.

11 Presti B, Guilhem I, Prieur NL. Capillary blood glucose monitor evaluation in a newborn nursery. Clin Pediatr 1989;28:412-15.

12 Kaplan M, Blondheim O, Alon I, et al. Screening for hypoglycemia with plasma in neonatal blood of high hematocrit value. Crit Care Med 1989;17:279-82.

13 Trajanoski Z, Wach P, Brunner GA, et al. Accuracy of home blood glucose meters during hypoglycemia. Diabetes Care 1996; 19:1412-15.

14 Meloy L, Miller G, Chandrasekaran MH, et al. Accuracy of glucose reflectance testing for detecting hypoglycemia in term newborns. Clin Pediatr 1999;38:717-24.

15 Ellis M, Manandhar DS, Manandhar N, et al. Comparison of two cotside methods for the detection of hypoglycaemia among neonates in Nepal. Arch Dis Child Fetal Neonatal Ed 1996;75:F122-5.

16 Girouard J, Bradburn NC, Forest JC, et al. Multicenter evaluation of the glucometer Elite XL meter, an instrument specifically designed for use with neonates. Diabetes Care 2000;23:1149-53.

17 Royal College of Pathologists of Australasia (RCPA). Quality Assurance Program 2003: General Serum Chemistry and Therapeutic Drugs Program.

18 Bland JM, Altman DG. Statistical methods for assessing agreement between two methods of clinical measurement. Lancet 1986:307-10.

19 McNamara PJ, Sharief N. Comparison of EML 105 and Advantage analysers measuring capillary versus venous blood glucose in neonates. Acta Paediatr 2001;90:1033-41.

20 Papp M, Sharief. Comparison of two strip test methods of whole blood glucose measurement in the neonatal period. Acta Paediatr 2001;90:1042-6.

21 Gabriely I, Wozniak R, Mevorach M, et al. Trancutaneous glucose measurement using near-infrared spectroscopy during hypoglycemia. Diabetes Care 1999;22:2026-32.

22 Baumeister FAM, Rolinski B, Busch R, et al. Glucose monitoring with long-term subcutaneous microdialysis in neonates. Pediatrics 2001;108:1187-92. 